\title{
PAROMA BUILDING
}

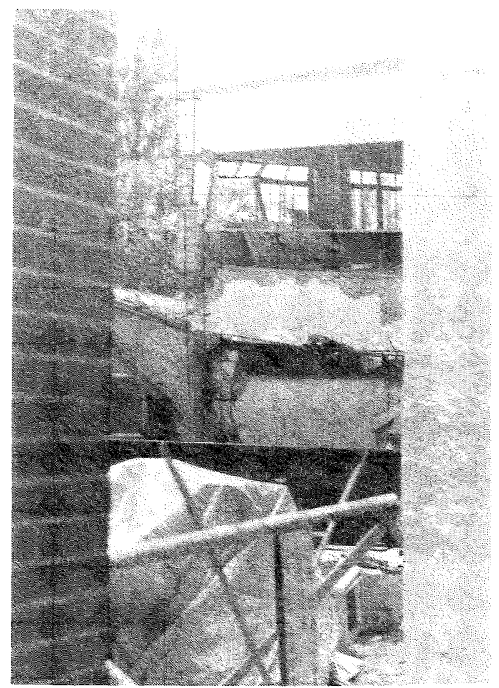

(1)

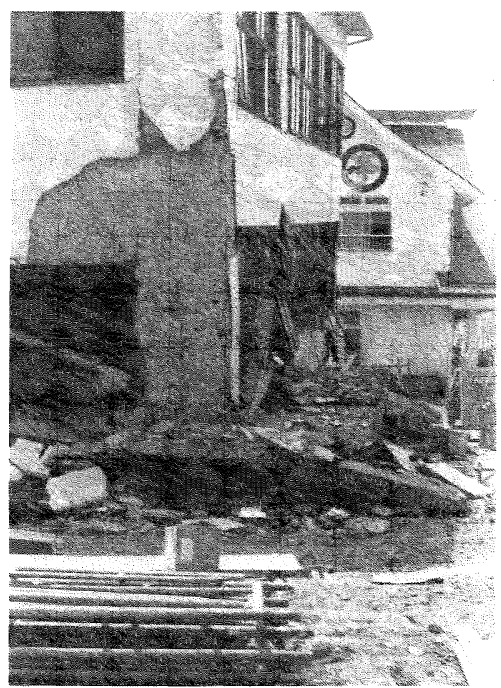

(2)

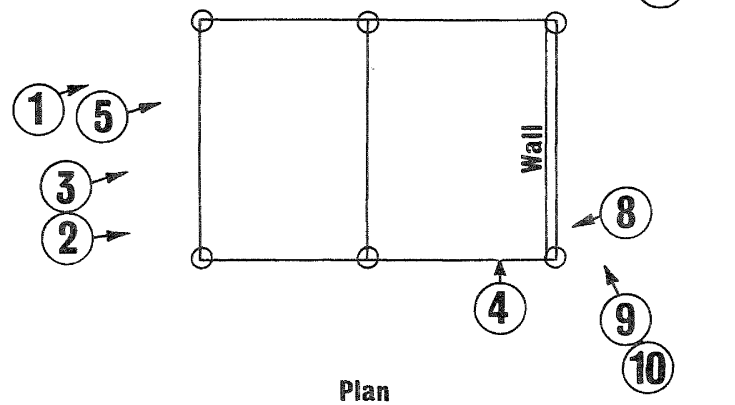

UNBALANGED LAYOUT OF STRUCTURAL ELEMENTS
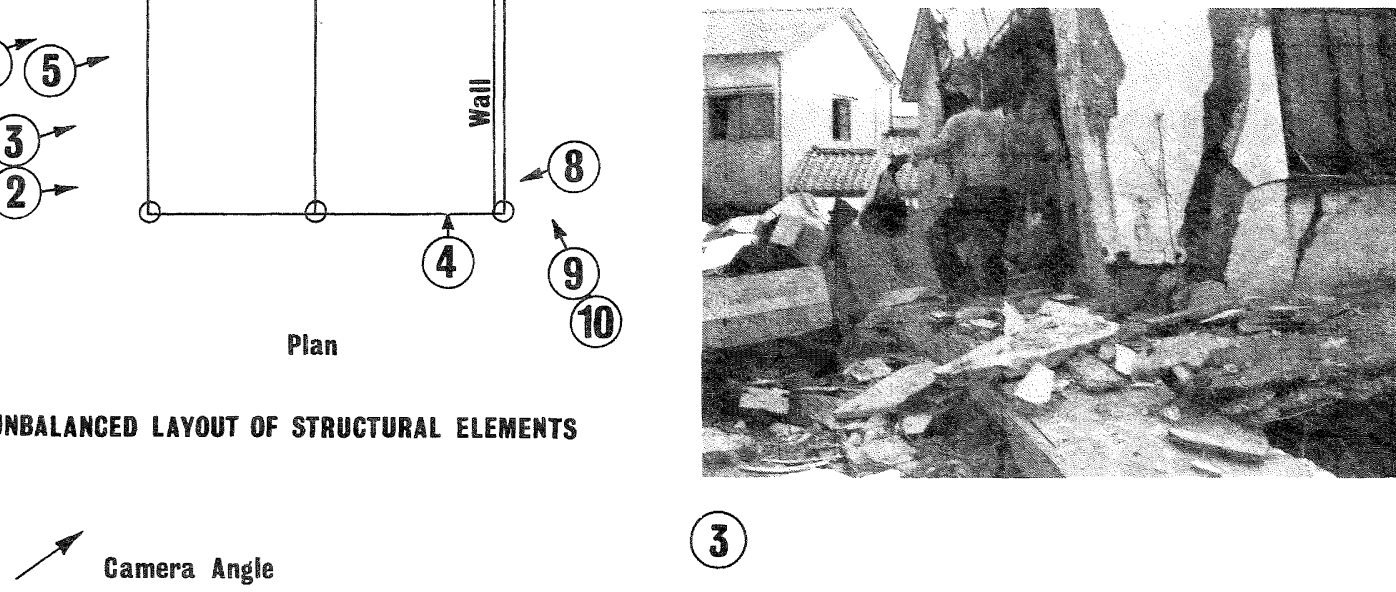

(3)
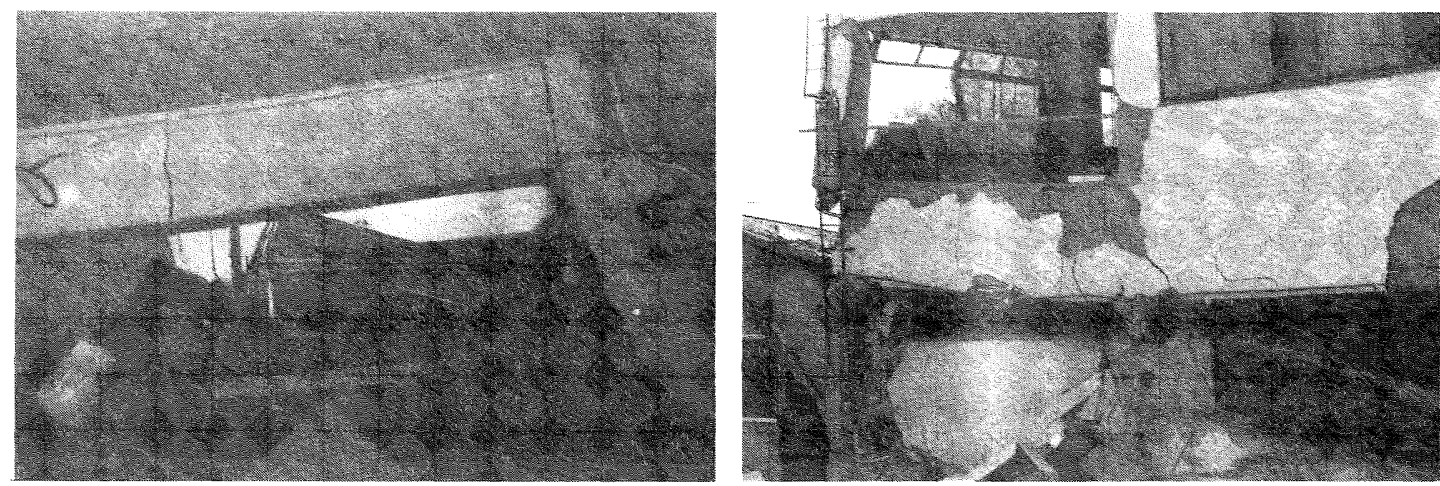

(4)

(5)

PHOTOGRAPHS OF BUILDING DAMAGE AT SENDAI, JAPAN, IN THE MIYAGIKEN-OKI EARTHQUAKE 12 JUNE 1978

The photographs on the next seven pages are of building damage in Sendai in the 12 June 1978 earthquake. The photographer was Doukou Hayashi of Yokayama Consulting Engineers, Tokyo, and are published here with the kind permission of Mr. W. P. Edwards. (See also Bulletin Vol.11 No.2) 


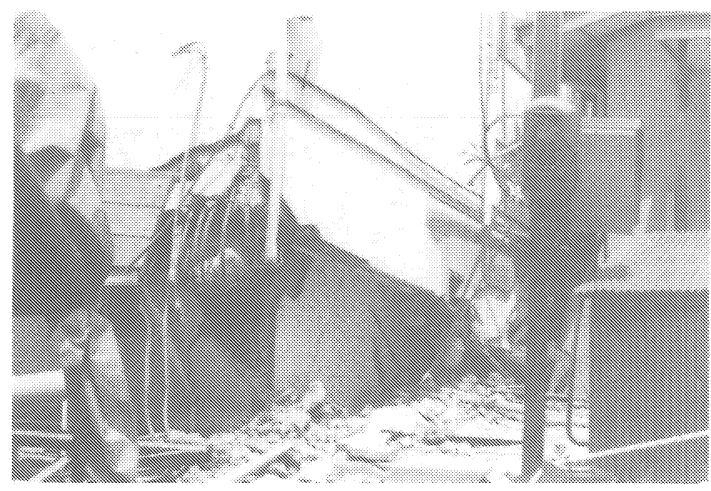

(6)

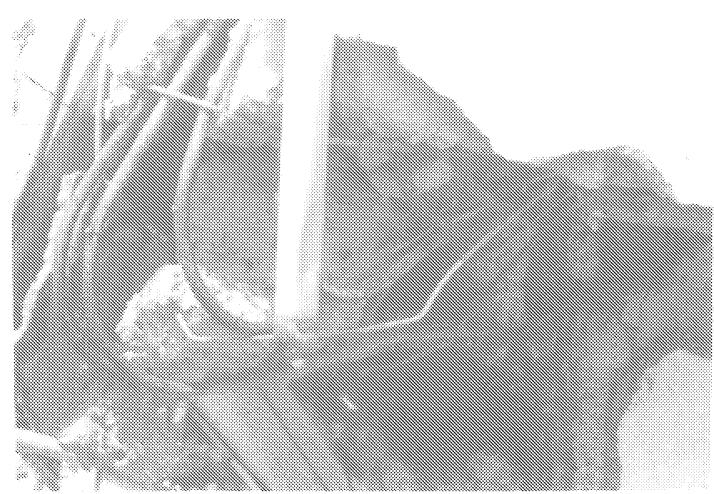

(7)

PAROMA BUILDING (continued)

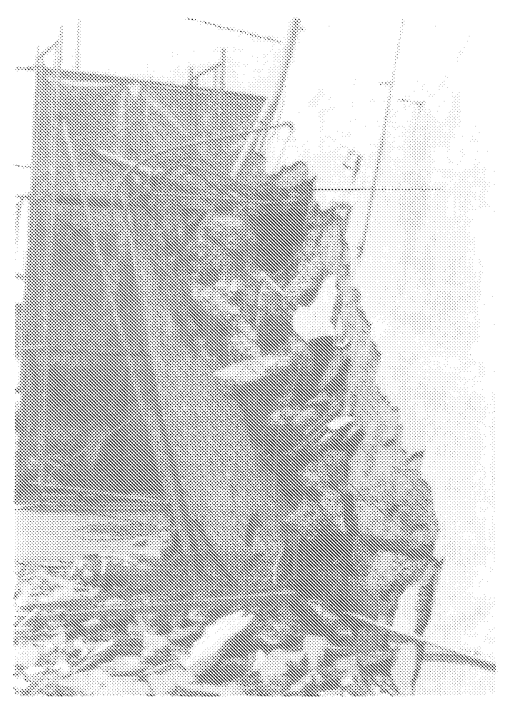

(8)
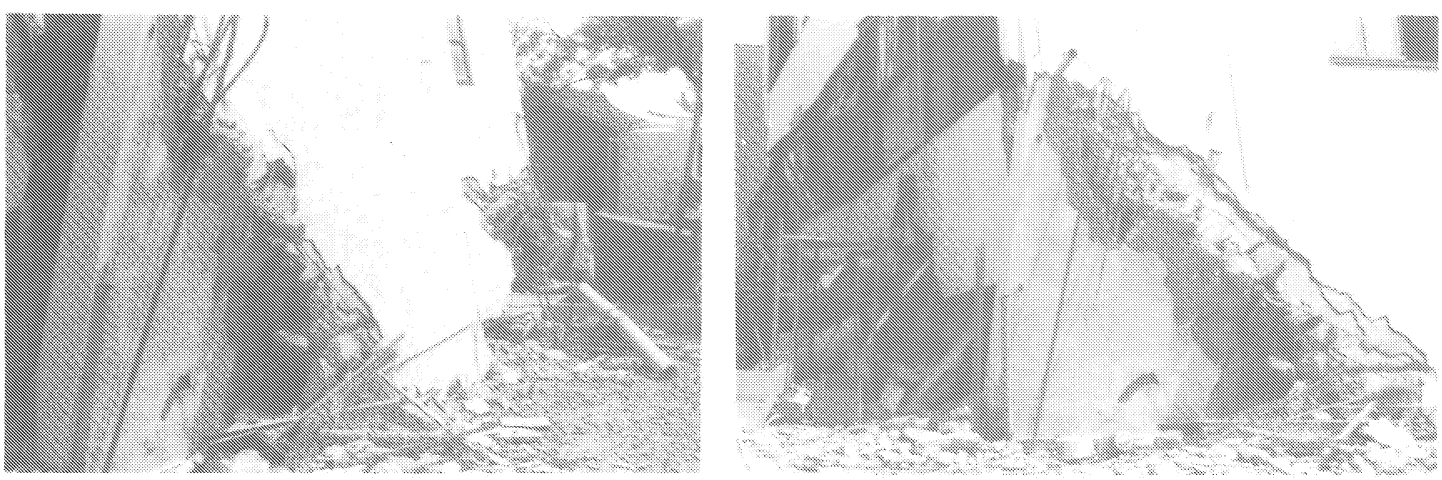

(9)

(10) 


\section{TOUHOUKU INSTITUTE OF TECHNOLOGY}

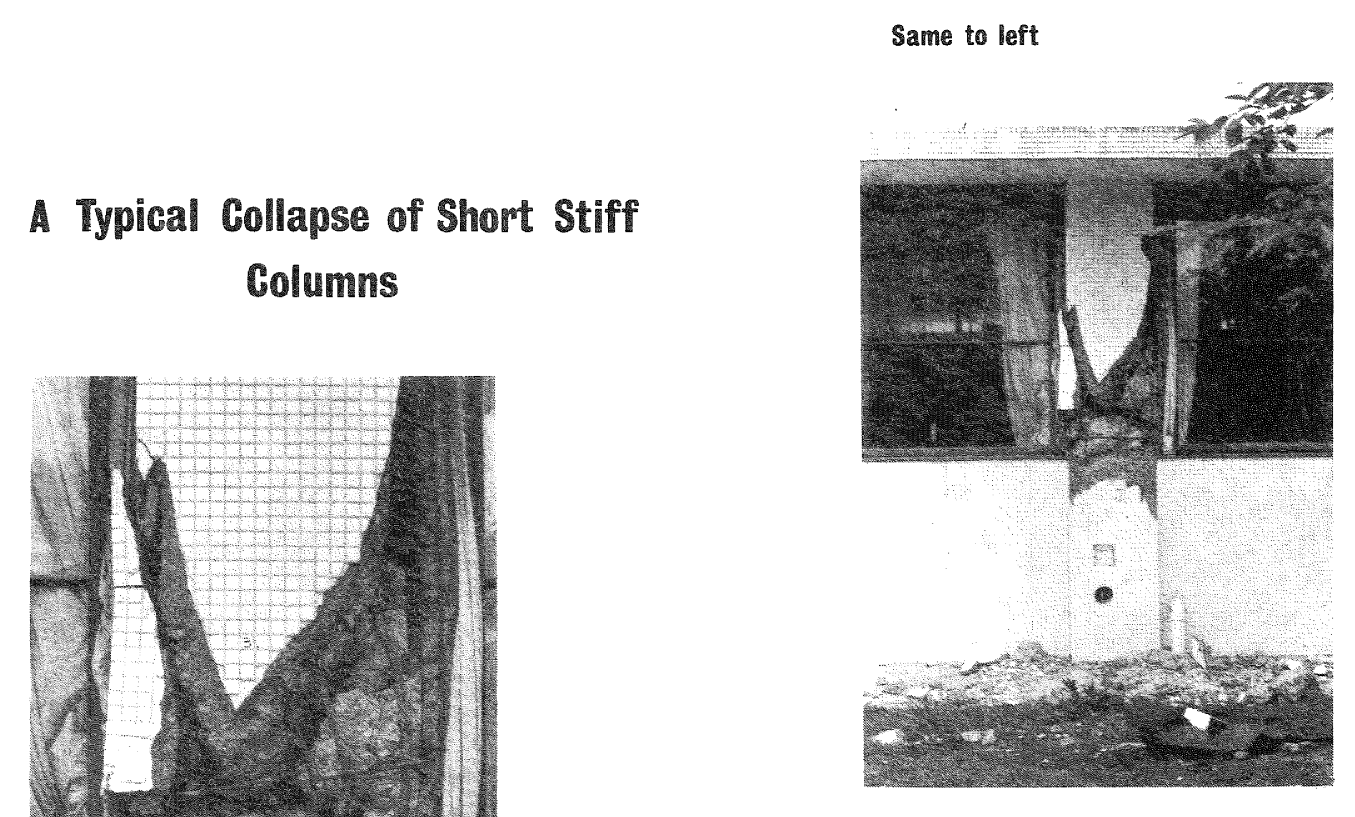

North Side
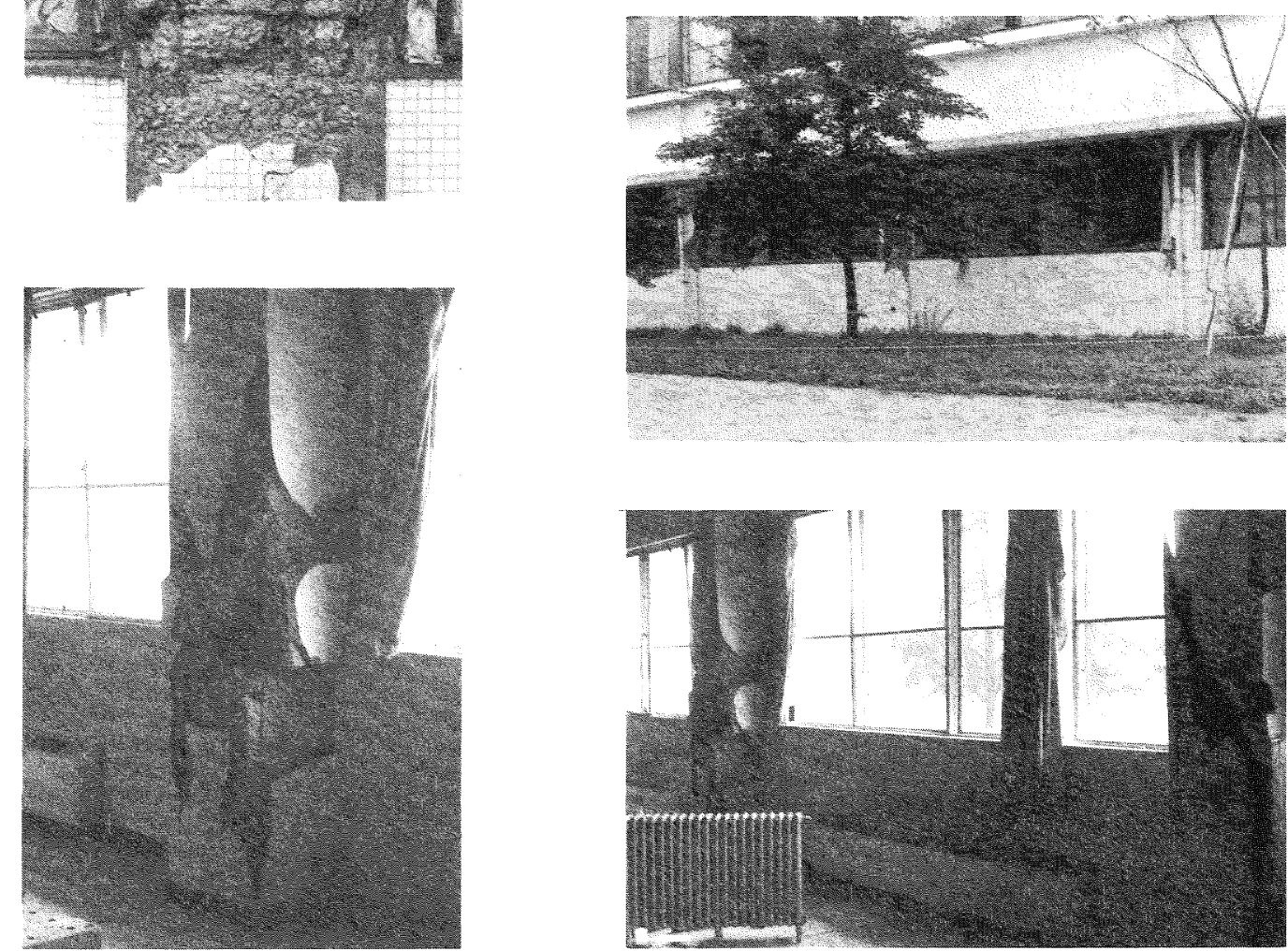

Inside of the column in upper photo

Same to left 

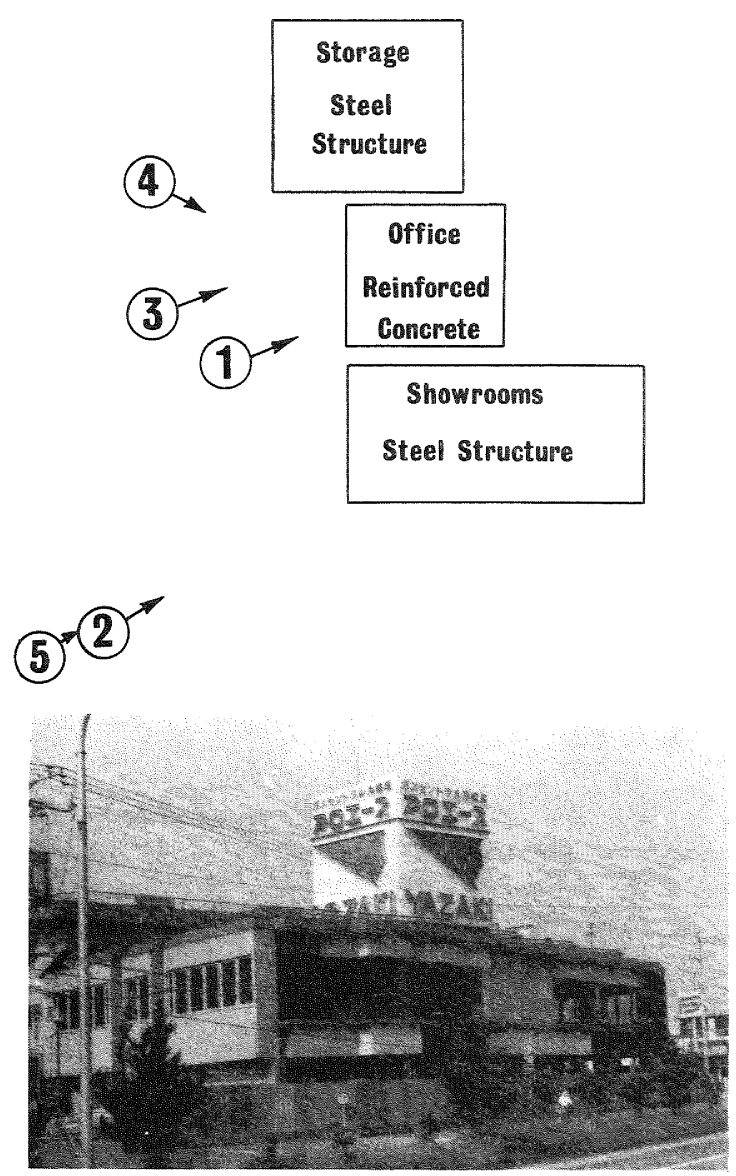

(2)

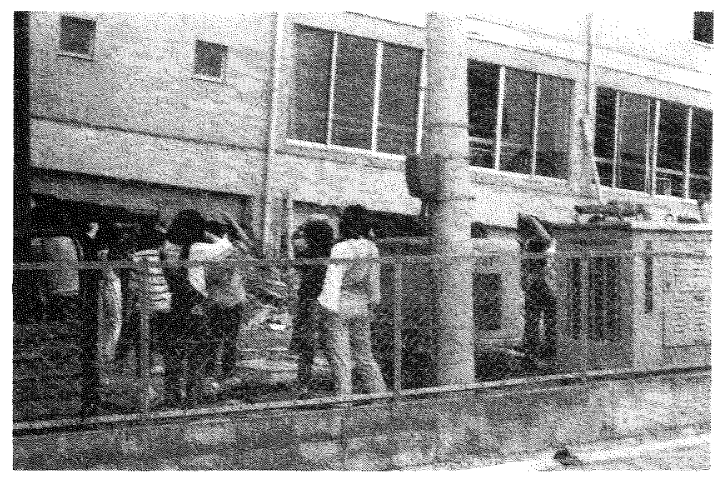

(4)

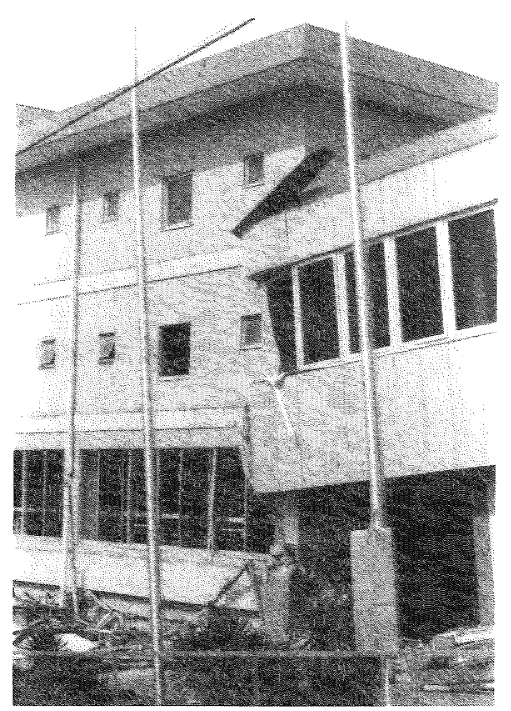

(1) 1st Floor Columns Collapsed

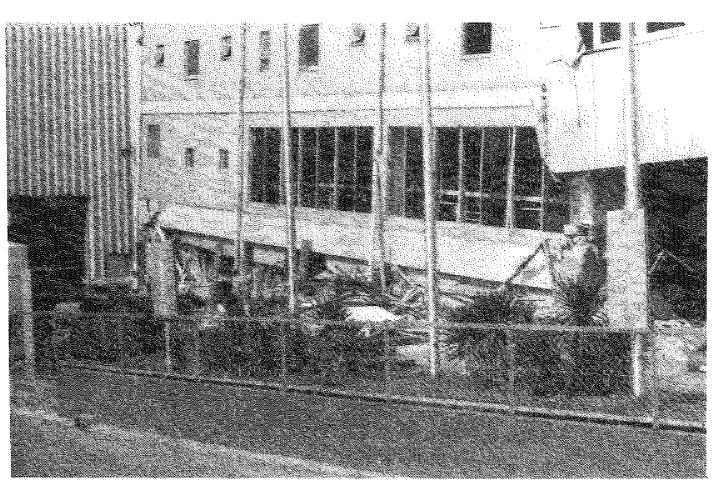

(3)

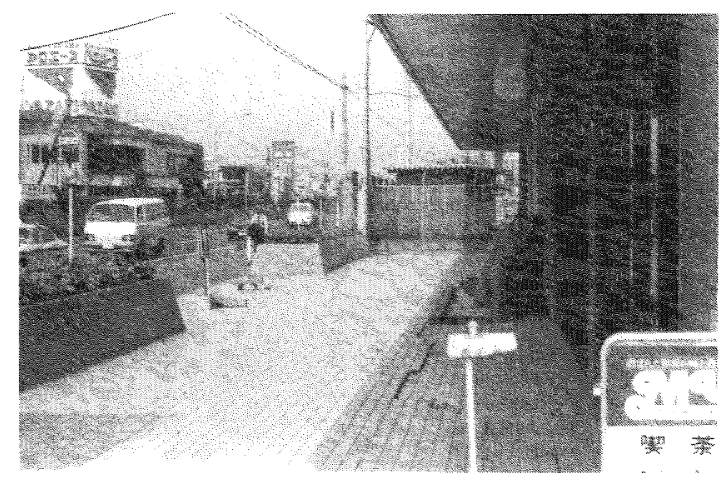

(5) Pavement is damaged (in many cases) 
This is the largest building which collapsed in the earthquake

\section{TAIYO FISHERY BUILDING}

Note Fallen Beer Grates
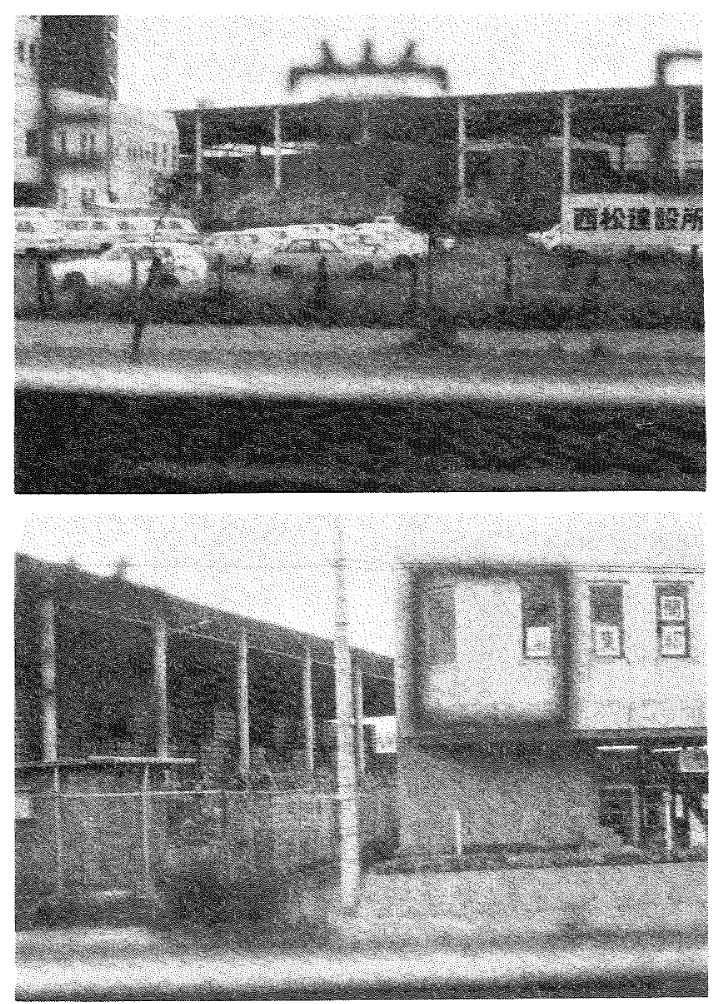

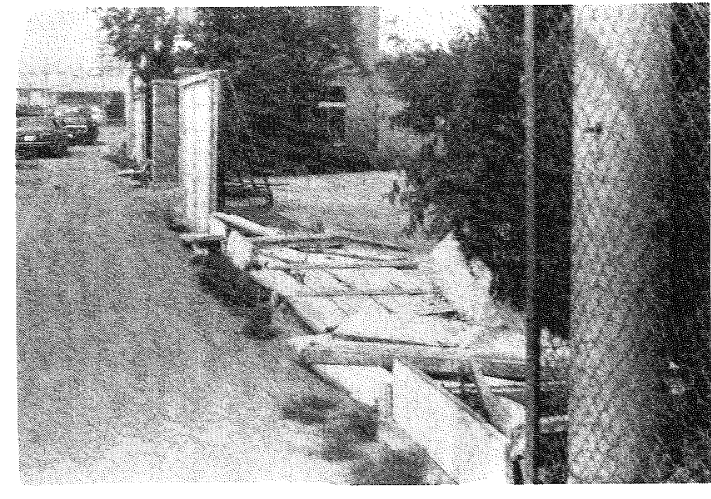

Precast Concrete Fences 
IZUMI HIGH SCHOOL

From East

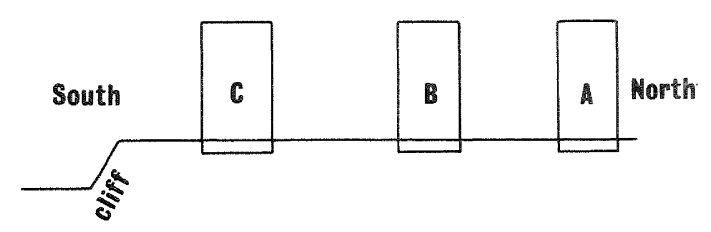

These three buildings have almost the same Structural System but C's damage is different from $A$ and $B$

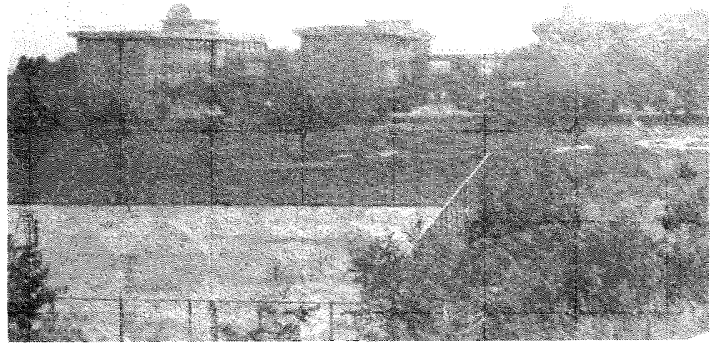

$C$ is founded on gravel

$N-$ Side of $A-B$

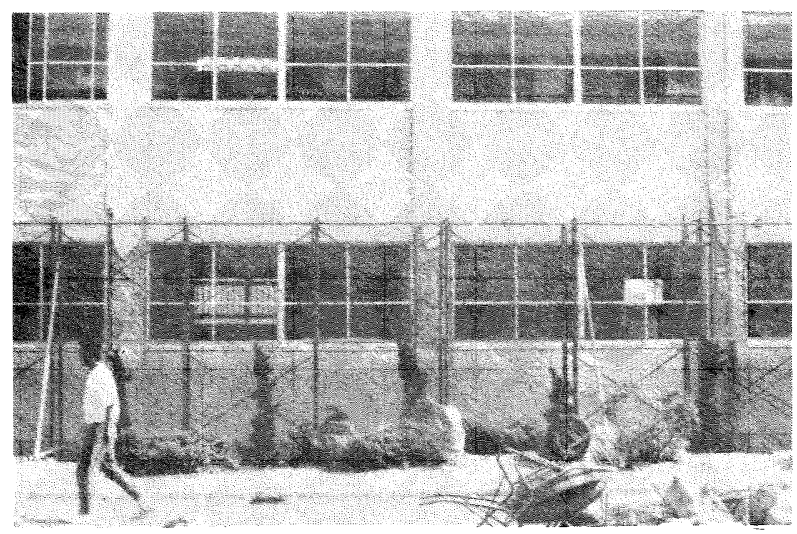

First Floor Columns are damaged, but hoops are so dense they aren't disolaced

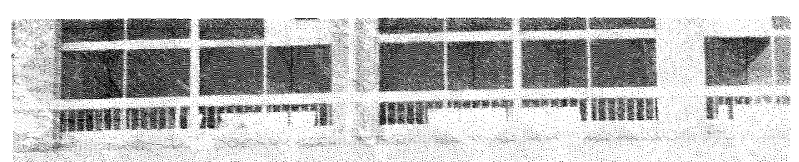

In General there are walls in alternate bays
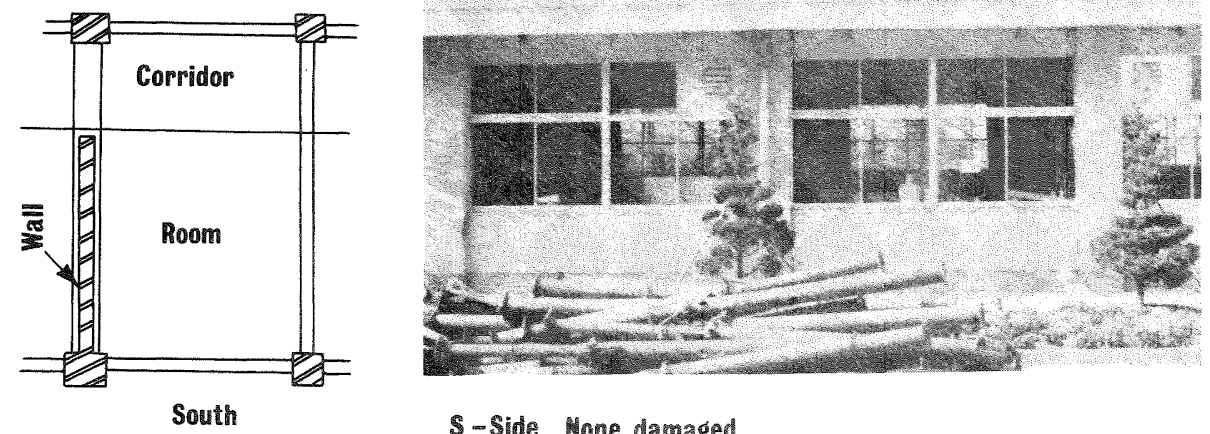

S-Side Mone damaged 


\section{IZUMI HIGH SCHOOL}

(continued)

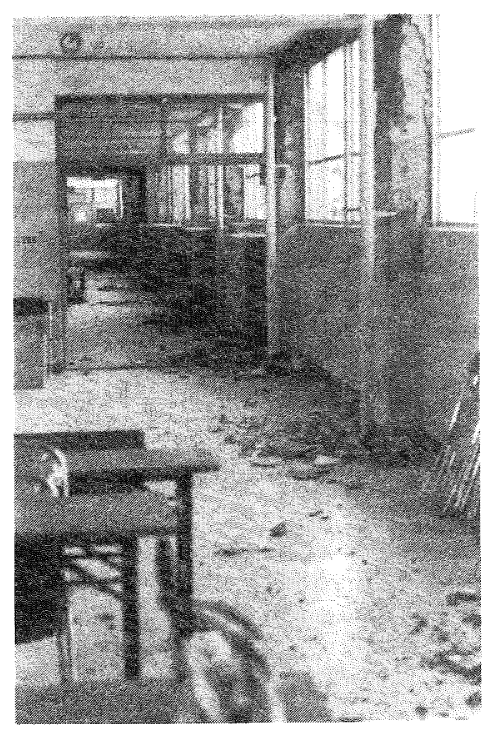

$\boldsymbol{N}$-Side from inside 1st Floor of $\mathrm{C}$

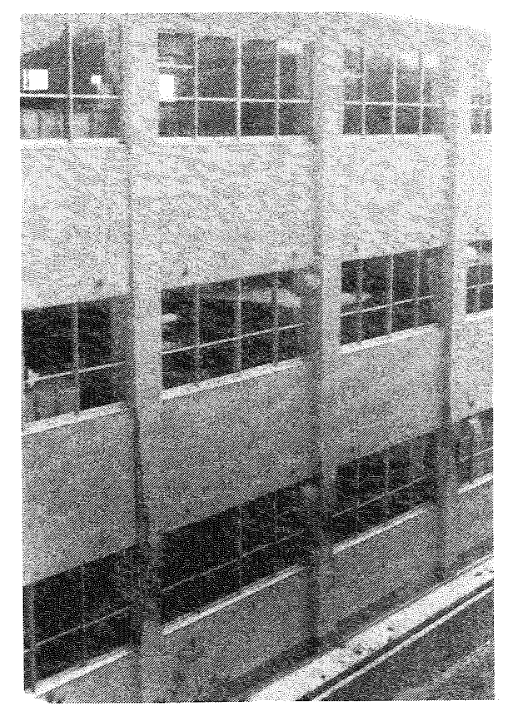

N-Side of $C$

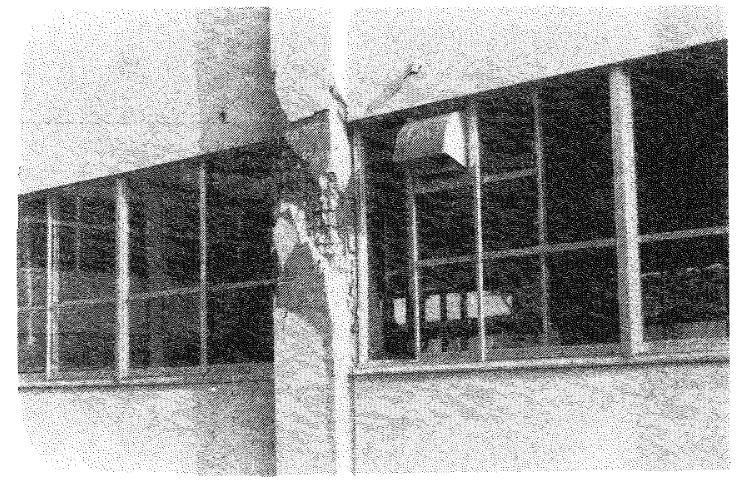

N-Side Ist Floor Column of C

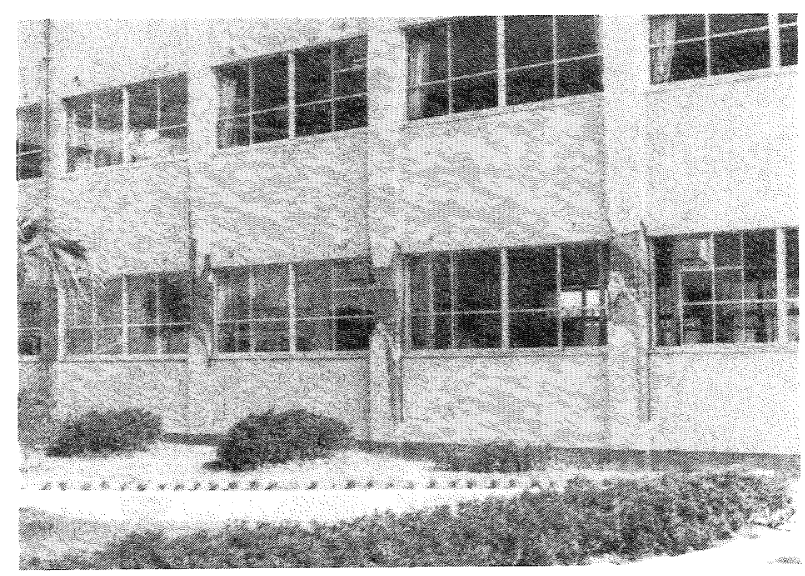

M-Side of C All 1st Floor Columns were yield

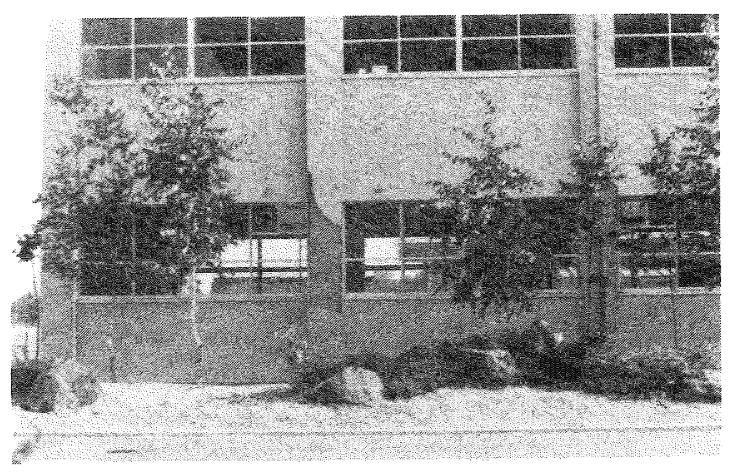

W - Side of $\mathrm{C}$ 